monográfico: Trasplante Renal. Experiencia del Hospital Clínico de Barcelona

Arch. Esp. Urol., 58, $6(481-484), 2005$

\title{
TRASPLANTE RENAL DE DONANTE CADÁVER: UMITACIONES DE UN MODELO
}

\author{
Jordi Vilardell Bergadà
}

Coordinación de Trasplantes. Hospita I C línico de Barcelona. España

\begin{abstract}
Resumen.- En 1965 se realizó el primer trasplante renal con éxito en España. Han pasado cua renta años, y en la actualidad España se constituye cómo el país con el índice de donantes de órganos procedentes de cadáver más alto del mundo. El llamado Modelo Español de Trasplantes es bien conocido por su organización y por sus excelentes resultados. Los resultados son fruto de una perfecta organización en red. En este sentido, la O rganización $N$ acional de Trasplantes $(0 \mathrm{~N} \mathrm{~T}$ ), las coordinaciones autonómicas, la red de hospitales, los coordinadores hospitalarios de trasplante $y$ todos los profesionales sanitarios implicados en el proceso de la donación y el trasplante, tienen perfectamente definidas sus funciones, y trabajan con el obje-
\end{abstract}

J. Vilardell Bergadà

Servicio de Coordinación de Trasplantes Hospital Clínico de Barcelona

C/ Villarroel, 170

08036 -Barcelona. (España).

e-mail: jvilar@clinic.ub.es tivo común de optimizar los recursos y de aprovechar las oportunidades.

Habida cuenta de que una de las características del Modelo Español de Trasplantes es la posibilidad de su adecuación a las necesidades del momento, a continuación se revisa y se hace un balance desde sus inicios hasta la actualidad.

Palabras clave: Trasplante renal. M odelo Español de Trasplantes

Summary.- The first successful kidney transplant in Spain was performed in 1965. It's been forty years already and currently Spain is the country with the highest cadaver donation rates world wide. The so-called Spanish model of transplantation is well known for its organization and excellent results. These results are the consequence of a perfect network organization. Furthermore, the organ procurement organization - O rganización N acional de Trasplantes-, regional coordinators, national health system hospital netw ork, hospital transplant coordinators, and all professionals involved in the process of donation and transplantation have perfectly well defined functions and work with the common objective of optimizing resources and making the most of the opportunities.

Provided that one of the main characteristics of the Spanish model is the possibility of adaptation to the moment's necessities, we proceed to review and evaluate it from its beginning to current days. 
Keywords: Kidney transplant. The Spanish model of transplantation.

\section{INTRODUCCIÓN}

Se acaba de cumplir el cincuenta aniversario del primer trasplante renal con éxito realizado por Joe Murray entre dos gemelos univitelinos en el Hospital Brigham de Boston, y próximamente se va a cumplir el cuarenta aniversario de la realización del primer trasplante renal de cadáver con éxito en el Estado español.

Este primer trasplante renal realizado en España puede considerarse el primer eslabón de una cadena de acontecimientos, tanto a nivel nacional como internacional, que han dado origen a un modelo organizativo de la donación y del trasplante, conocido como Modelo Español de Trasplantes. Este modelo ha sido mimetizado y adaptado por muchos países, a la vez que elogiado y criticado por profesionales y organizaciones de trasplante de todo el mundo.

En la actualidad, España encabeza la lista de países con un mayor índice de donantes cadavéricos por millón de población, 34,6 (p.m.p.) en el año 2004, que permite la realización de un importante número de trasplantes, pero que no consigue disminuir, de forma significativa, las listas de pacientes en espera. Ante esta realidad, parece razonable revisar el modelo actual, ponderando sus pros y contras y ante la realidad de los avances científicos, definir nuevas estrategias de actuación y priorizarlas.

\section{Nacimiento de un modelo.}

El primer trasplante renal de cadáver con éxito en el Estado español se realizo en abril de 1965, concretamente en el Hospital Clínico de Barcelona, en el Servicio de Urología, bajo la dirección de los profesores José Ma Gil-Vernet y Antonio Caralps. Unos meses más tarde la Fundación Jiménez Díaz de Madrid también inició su programa de trasplantes.

En 1970, se crearon en España los primeros laboratorios de histocompatibilidad. En la década de los setenta, la histocompatibilidad adquirió una gran importancia a la hora de seleccionar a los receptores para trasplante; en este sentido, se buscaba la máxima compatibilidad entre donante y receptor con la finalidad de obtener unos mejores resultados. Este hecho determinó la creación de organizaciones nacionales e internacionales con el objetivo primordial de coordinar y facilitar el intercambio de los riñones para trasplante.

En esta época se llevaban a cabo muy pocos trasplantes renales, y una parte importante de ellos se realizaba con riñones procedentes de donante vivo, habida cuenta de que no era fácil obtener órganos procedentes de donante cadáver, al no estar definido y aceptado el concepto de "muerte encefálica", y en este contexto, en el caso de un paciente en esta situación clínica, se debía de esperar a que se produjera una parada cardiorrespiratoria para, a continuación, poder proceder a la extracción de los riñones para trasplante, previa solicitud de la autorización a la familia del paciente fallecido. Por aquel entonces, la sociedad española estaba muy poco informada, y mucho menos sensibilizada, de la importancia de la donación de los órganos para poder realizar los trasplantes de riñón, y solamente un grupo reducido de profesionales de la sanidad, ni siquiera muchos especialistas, reconocían las ventajas que podía aportar a corto y largo plazo el trasplante renal, en un momento en que el tratamiento de la insuficiencia renal terminal con la diálisis (peritoneal y hemodiálisis) se empezaba a ofrecer a unos grupos seleccionados de pacientes. A pesar de todas estas circunstancias, el número total de trasplantes realizados en España en el año 1978, por primera vez llegó a los 100.

La promulgación de la Ley 30/1979 de 27 de octubre, sobre extracción y trasplantes de órganos, y un total de 192 trasplantes renales realizados a 10 largo del año 1979 ponen un broche de oro a la década de los 70.

En relación a los avances científicos de esta época, cabe hacer referencia al descubrimiento de la ciclosporina A, en 1976, por Borel, y a los trabajos publicados por Calne en relación a su utilización en el hombre.

\section{Expansión del modelo. Los gloriosos años 80.}

La actividad de trasplante renal en España durante los años 80 viene marcada por un aumento progresivo de los centros de trasplante renal y de la actividad trasplantadora, que parecía imparable, que 
tras alcanzar un máximo de 1182 trasplantes de riñón en 1986 , descendió un $20 \%$ durante 1987 , descenso que se mantuvo en 1988 y 1989. Estos hechos motivaron la denuncia de las asociaciones de enfermos renales, elevando sus quejas al Defensor del Pueblo. A finales de 1989, como consecuencia de estos hechos, inició su andadura la Organización Nacional de Trasplantes (O NT), con el objetivo de establecer un sistema coordinador propio, adaptado a las características sanitarias y a la realidad del país. Con una estructura firme a la vez que flexible en el tiempo, basada en pilares estudiados y bien razonados, pero capaz de adaptarse a los cambios y, o las necesidades.

En 1984 surge en nuestro país, concretamente en Cataluña, la figura del coordinador hospitalario de trasplantes como resultado de la necesidad de poder contar con una persona con conocimientos técnicos y administrativos, debido a que este mismo año se pusieron en marcha otros programas de trasplante no renal, como el trasplante hepático y el cardíaco, que convertían al donante de órganos en multiorgánico, y se necesitaba una persona que coordinara a los diferentes equipos de extracción.

\section{La década de los trasplantes.}

A sí llama R. Matesanz a los años 90, en que el número de trasplantes renales en España aumentaba año tras año, a la vez que se constituían nuevos equipos de esta modalidad de trasplante. En el año 1999, se realizaron un total de 2023 trasplantes. La década finaliza con la promulgación del Real Decreto 2070/ 1999 de 30 de diciembre, que regula la extracción de órganos en muerte por parada cardiorrespiratoria, y establece y concreta los requisitos a seguir para la donación de órganos para trasplante en vida. Cabe señalar que, a lo largo de los años noventa se observó un cambió en el perfil del donante. En este sentido, se pudo observar cómo aumentaban el número de donantes de órganos procedentes de muertes a causa de accidentes vasculares cerebrales, a la vez que disminuía el número de donantes a consecuencia de traumatismos craneoencefálicos, este hecho supuso un aumento de la media de edad de los donantes. Paralelamente, y como consecuencia de los buenos resultados del trasplante renal, el número de indicaciones de trasplante renal aumentaba año tras año, en este sentido, se ofrecía la oportunidad de un trasplan- te renal a muchos pacientes que no se habían considerado candida tos anteriormente.

En el transcurso de esta década aparecieron nuevos fármacos inmunosupresores, abriéndose nuevos caminos en el tratamiento del rechazo en todas sus manifestaciones.

\section{¿Hacia un nuevo modelo de trasplantes?}

A ctualmente, y en relación a la donación de cadáver, todavía es posible aumentar el número de donantes, ávida cuenta que, por un lado, la población española aumenta año tras año, y por otro, aún podemos disminuir las negativas del ciudadano a la donación, actualmente alrededor del $18 \%$.

En relación a los recursos materiales, contamos con un total de 41 equipos de trasplante renal distribuidos por toda la geografía, prácticamente todas los Servicios de Salud tienen en su cartera de prestaciones uno o más programas de trasplante renal en la propia Comunidad (excepto La Rioja y las Ciudades A utónomas de Ceuta y M elilla), que realizan al año un número importante de trasplantes de riñón con buenos resultados tanto en lo que se refiere a la supervivencia del paciente como del injerto.

Sin embargo, es necesario buscar y potenciar nuevas alternativas para poder dar respuesta al aumento de la demanda $y$, en este sentido, el trasplante de riñón procedente de donante vivo se constituye cómo una alternativa válida, perfectamente regulada y que ofrece unos excelentes resultados, que puede beneficiar a todo aquel paciente que disponga de un donante adecuado, e indirectamente al resto de pacientes que, no teniendo la misma suerte, pueden ver cómo se reduce la espera, de forma significativa, a expensas de aquellos que pueden recibir un trasplante de donante vivo.

O tras soluciones para ampliar el pool de donantes, pasan por potenciar programas de obtención de órganos a partir de donantes en asistolia, como el programa del Hospital Clínico San Carlos de Madrid o del Hospital Clínico de Barcelona, que a lo largo de los años han demostrado su eficacia en la obtención de órganos sólidos válidos para trasplante. En relación a la optimización de órganos para trasplante, cabe hacer mención a los programas de tras- 
plante doble de riñón del Hospital 12 de 0 ctubre de Madrid y del Hospital de Bellvitge de Barcelona, por citar a los equipos con mayor actividad y más experiencia en este tipo de trasplantes en España.

O tra solución pasa por la ampliación de criterios de aceptación de donantes, en relación a pacientes con antecedentes de ciertas neoplasias 0 algunas infecciones, hasta ahora no aceptados como donantes, y que en un futuro sus órganos podrían ser utilizados para trasplantar a determinados grupos de pacientes en situación de urgencia vital, previa obtención del consentimiento informado.

La distribución e intercambio de órganos para trasplante merece también algunos comentarios. En este sentido, se hace necesario revisar estos criterios con la única finalidad de que todos los ciudadanos tengan las mismas oportunidades de trasplante.

Posiblemente, el modelo español de trasplantes sigue vigente en la actualidad, si bien necesita de algunos cambios y ajustes, debido al paso del tiempo y de los avances científicos. Sin embargo, todo cambio debería de ser fruto del diálogo y consenso de todos los profesionales implicados en todo el proceso de la donación y el trasplante, tal y cómo se ha venido haciendo hasta el momento actual. Cualquier otro sistema utilizado podría ir en contra de los resultados esperados.

\section{BIBUOGRAFIA y LECTURAS RECOMENDADAS (*lectura de interés y **lectura fundamental)}

1. MERRILL, J.P.; MURRAY, J.E.; HARRISON, J.H. y cols.: "Successful homotransplantation of the human kidney”. JAMA, 160: 277, 1956.
2. CARALPS, A.; GIL-VERNET, J.M.; VIVES, J. y cols.: "Trasplante Renal". Capítulo 1: 3-8. Editorial Toray S.A. Barcelona, 1983.

**3. MATESANZ, R.; MIRANDA, B.: "A decade of continuous improvement in cadaveric organ donor; the Spanish model". J. Nephrol., 15: 22, 2002. **

*4. MANYALICH, M.; CABRER, C.; VILARDELL, J. y cols.: "Functions, responsibilities, dedication, organization and profile oh the hospital transplant coordination in Spain 2002" . Transplant Proc., 35: 1633, 2003.

**5. CHANG, G.J.; MAHANTY, H.D.; ASCHER, N.L. y cols.: "Expandig the donor pool: can the Spanish model work in the United States?'. Am. J. Transplant, 3: 1188, 2003.

*6. WIGHT, J.; JAKUBOVIC, M.; WALTERS, S. y cols.: "Variation in cadaveric organ donor rates in the UK". Nephrol Dial Transplant, 19: 963, 2004.

**7. MIRANDA, B.; VILARDELL, J.; GRINYO, J.M.: "Optimizing cadaveric organ procurement: the catalan and Spanish experience". Am. J. Transplant, 3: 1185, 2003.

*8. NANNI COSTA, A.; PUGLIESE, M.R.; VENTUROLI, N. y cols.: "The transplant coordinator". Ann. Ist. Super Sanita., 36: 247, 2000.

**9. LOPEZ-NAVIDAD, A.; KULISEVSKY, J.; CABALLERO, F.: "El donante de órganos y tejidos. Evaluación y manejo". Capítulo 4. Springer-Verlag Ibérica. Barcelona, 1997.

**10. LOPEZ-NAVIDAD, A.; KULISEVSKY, J.; CABALLERO, F.: "El donante de órganos y tejidos. Evaluación y manejo”. Capítulo 5. Springer-Verlag Ibérica. Barcelona, 1997.

*11. PARK, K.; LEE, J.H.; HUH, K.H, y cols.: "Exchange living-donor kidney transplantation: Diminution o donor organ shortage". Transplant Proc., 36: 2949, 2004.

*12. DEL RIO GALLEGOS, F.; NUÑEZ PEÑA, J. R.; SORIA GARCIA, A. y cols.: "Non heart beating donors. Succesfully expanding the donor's pool". Ann Transplant, 9: 19, 2004.

*13. BOGGI, U.; PIETRABISSA, A.; VISTOLI, F. y cols.: "Simultaneous pancreas-kidney transplantation is improved by living kidney donation program". Transplant Proc., 36: 1061, 2004.

14. BOREL, J.F.; FEURER, C.; MAGNE, C. y cols.: "Effects of the new antilymphocytic cyclosporin A in animals". Immunology, 32: 1017, 1977.

15. CALNE, R.; ROLLES, K.; WHITE, D.J.G. y cols.: "Cyclosporin A initially as the only immunosuppressant in 34 recipients of cadaveric organs: 32 kidney, 2 pancreas and 2 livers". Lancet, 2: 1033, 1979. 